\section{Commentary: Close but not quite unequivocally unequivocal}

\author{
Ernest G. Chan, MD, MPH, ${ }^{\mathrm{a}}$ and \\ J. W. Awori Hayanga, MD, MPH ${ }^{\mathrm{b}}$
}

In their article, Hoetzenecker and colleagues ${ }^{1}$ describe their experience with bilateral lung transplantations performed between 2016 and 2017. They preferentially used central venoarterial extracorporeal membrane oxygenation (ECMO) support as the mechanical support of choice. The prospective study was conducted in a center with a solid foundation and track record in transplantation. Nevertheless, the single-armed, nonblinded, nonrandomized design tempers the authoritativeness by which any claims may subsequently be made. Despite the absence of an explicit comparative arm, the authors hypothesize that ECMO would lower rates of primary graft dysfunction. Indeed, it is on this premise that the design is hinged and the conclusion framed. The authors allude to one of their previous publications, referring to this as a comparative cohort in whom transplantation was performed without mechanical support. ${ }^{2}$ This method of comparison is a departure somewhat from standard statistical theory and, without a more rigorous adjudication and risk adjustment, conjures a sense of conjecture.

The addition of a comparison arm with either cardiopulmonary bypass or no support would have more persuasively represented a more meaningful alternative, taking into consideration the high prevailing clinical acuity that typically dictates the need for mechanical support. The acuity, or the lack thereof, is pertinent given the median lung allocation scores of 39 reported in the study. Recipients with scores from 34 to 48 may not necessarily have crossed the

\footnotetext{
From the a Division of Thoracic Surgery, Department of Cardiothoracic Surgery, University of Pittsburgh Medical Center, Pittsburgh, Pa; and ${ }^{\mathrm{b}}$ Department of Cardiovascular and Thoracic Surgery, West Virginia University, Morgantown, WVa. Disclosures: The authors reported no conflicts of interest.

The Journal policy requires editors and reviewers to disclose conflicts of interest and to decline handling or reviewing manuscripts for which they may have a conflict of interest. The editors and reviewers of this article have no conflicts of interest.

Received for publication June 24, 2020; revisions received June 24, 2020; accepted for publication June 24, 2020; available ahead of print July 12, 2020.

Address for reprints: J. W. Awori Hayanga, MD, MPH, Department of Cardiovascular and Thoracic Surgery, West Virginia University, 1 Medical Center Drive, Morgantown, WV 26506 (E-mail: jhayanga@me.com).

J Thorac Cardiovasc Surg 2022;164:e35-6

$0022-5223 / \$ 36.00$

Copyright (C) 2020 by The American Association for Thoracic Surgery

https://doi.org/10.1016/j.jtcvs.2020.06.100
}

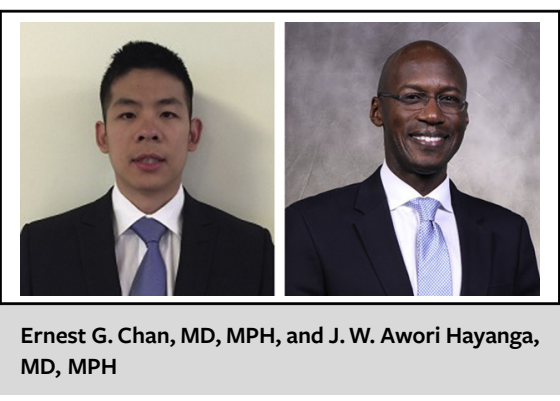

CENTRAL MESSAGE

ECMO for intraoperative support during lung transplantation.

threshold for intraoperative mechanical support in many centers in the United States. ${ }^{3}$ Furthermore, the absence of concomitant cardiothoracic procedures such as coronary artery bypass graft or closure of patent foramen ovale would also limit comparability and any generalization as to the choice of support.

During the conduct of the procedure, the authors opted against the measurement of activated clotting time and, as such, against any discernible record of the extent of anticoagulation used. This decision serves as a detractor in the calculus of testimony against cardiopulmonary bypass, because increased bleeding risk is often cited as a reason against cardiopulmonary bypass. The authors thus chose against collecting evidence that might have served to strengthen their assertion. Regardless, the choice between intraoperative ECMO support versus cardiopulmonary bypass is pertinent and relevant. There have been contentious arguments for and against both. ${ }^{4-8}$ The authors have, without question, cataloged excellent outcomes in this specific cohort of patients, and for this, they deserve congratulations. The absence of a comparative arm, the relatively lower acuity of the recipients, and the myriad sources of confounding and bias proffered by the lack of risk adjustment each independently weaken their argument and despite growing enthusiasm for ECMO serve to generate more questions than answers.

\section{References}

1. Hoetzenecker K, Benazzo A, Stork T, Sinn K, Schwarz S, Schweiger T, et al. Bilateral lung transplantation on intraoperative extracorporeal membrane oxygenator: an observational study. J Thorac Cardiovasc Surg. 2020;160:320-7.e1.

2. Hoetzenecker K, Schwarz S, Muckenhuber M, Benazzo A, Frommlet F, Schweiger T, et al. Intraoperative extracorporeal membrane oxygenation and the possibility of postoperative prolongation improve survival in bilateral lung transplantation. J Thorac Cardiovasc Surg. 2018;155:2193-206.e3. 
3. Russo MJ, Iribarne A, Hong KN, Davies RR, Xydas S, Takayama H, et al. High lung allocation score is associated with increased morbidity and mortality following transplantation. Chest. 2010;137:651-7.

4. Bermudez CA, Shiose A, Esper SA, Shigemura N, D'Cunha J, Bhama JK, et al Outcomes of intraoperative venoarterial extracorporeal membrane oxygenation versus cardiopulmonary bypass during lung transplantation. Ann Thorac Surg. 2014;98:1936-42.

5. Tong MZ. Con: extracorporeal membrane oxygenation should not routinely replace cardiopulmonary bypass as the preferred method of support during lung transplantation. J Cardiothorac Vasc Anesth. 2017;31:1509-10.
6. Mohite PN, Sabashnikov A, Patil NP, Garcia-Saez D, Zych B, Zeriouh M, et al The role of cardiopulmonary bypass in lung transplantation. Clin Transplant 2016;30:202-9.

7. Bates M, Factor M, Parrino PE, Bansal A, Rampolla R, Seoane L, et al. Lung transplantation and the routine use of cardiopulmonary bypass and median sternotomy experience at the Ochsner multi-organ transplant institute. Ochsner J. 2017;17: $38-41$

8. Taka H, Miyoshi K, Kurosaki T, Douguchi T, Itoh H, Sugimoto S, et al. Lung transplantation via cardiopulmonary bypass: excellent survival outcomes from extended criteria donors. Gen Thorac Cardiovasc Surg. 2019;67:624-32. 